\title{
Morfo-anatomia do sistema subterrâneo de Calea verticillata (Klatt) Pruski e Isostigma megapotamicum (Spreng.) Sherff - Asteraceae ${ }^{1}$
}

\author{
DIVINA A.A. VILHALVA² e BEATRIZAPPEZZATO-DA-GLÓRIA ${ }^{3,4}$
}

(recebido: 7 de outubro de 2004; aceito: 29 de dezembro de 2005)

\begin{abstract}
Morpho-anatomy of the subterranean system of Calea verticillata (Klatt) Pruski and Isostigma megapotamicum (Spreng.) Sherff - Asteraceae). Several herbaceous species from "cerrado" (savana like vegetation) have thickened subterranean systems, which may be of root and/or stem nature. These systems have bud shoot-forming potential, providing the sprout of new shoots after an adverse period, like a severe drought or a burning. The verification of the subterranean systems nature is extremely important to the correct terminology usage. This work aimed to present information about subterranean systems morphology and anatomy of Calea verticillata and Isostigma megapotamicum, placing emphasis on the shoot-buds development. The subterranean systems were collected from "cerrado" areas of São Paulo State. The anatomical structure in C. verticillata is of both stem and root nature, with self-grafting of both shoots and roots, whereas in I. megapotamicum, the anatomical structure is caulinar, with self-grafting of shoots. Both species are composed of xylopodium with a high bud shootforming potential, whose buds are exclusively formed in the cambium. Secretory ducts occur in these species. The microchemical test, accomplished with Sudan black B, stained the oily nature of the secretion. Crystals of inulin were visualized by polarized light in I. megapotamicum. The high bud shoot-forming potential, present in the subterranean systems of both species here analyzed, improves their survival perspectives when they are submitted to the "cerrado" adverse conditions, by providing the sprouting of new shoots in favourable periods.
\end{abstract}

Key words - anatomy, buds, "cerrado", storage, xylopodium

RESUMO - (Morfo-anatomia do sistema subterrâneo de Calea verticillata (Klatt) Pruski e Isostigma megapotamicum (Spreng.) Sherff - Asteraceae). Várias espécies herbáceas do cerrado apresentam sistema subterrâneo espessado, esses podem ser de natureza radicular, caulinar ou mista. Esses sistemas muitas vezes possuem potencial gemífero, promovendo o rebrotamento de ramos aéreos após um período desfavorável do ambiente, como uma seca prolongada ou uma queimada. A verificação da natureza dos sistemas subterrâneos é de extrema importância para utilização correta da terminologia dos mesmos. O objetivo desse trabalho foi fornecer informações sobre a morfo-anatomia dos sistemas subterrâneos de Calea verticillata e Isostigma megapotamicum, com ênfase na formação de gemas caulinares. Os sistemas subterrâneos foram coletados em áreas do cerrado do Estado de São Paulo. As espécies apresentam sistema subterrâneo bastante complexo, com estrutura anatômica mista, lignificada, auto-enxertias de ramos e raízes e elevada capacidade gemífera, ambas espécies são providas de xilopódios e as gemas têm origem cambial. Foi verificada a presença de canais secretores em C. verticillata e em I. megapotamicum, originados a partir de células derivadas do câmbio vascular. O teste microquímico realizado com Sudan black B confirmou a natureza lipídica da secreção. Em I. megapotamicum foi verificada a presença de cristais de inulina sob luz polarizada. Os sistemas subterrâneos aumentam as chances de sobrevivência das duas espécies estudadas às condições adversas do cerrado, pois apresentam alto potencial gemífero, promovendo o rebrotamento de ramos aéreos durante a estação favorável.

Palavras-chave - anatomia, cerrado, gemas, reservas, xilopódios

\section{Introdução}

Cerca de cinqüenta por cento da vegetação herbácea e subarbustiva do bioma cerrado apresenta órgão subterrâneo espessado, o que sugere a importância ecológica dessas estruturas (Mantovani \& Martins

1. Parte da dissertação de mestrado do primeiro autor, Programa de Pós-Graduação em Biologia Vegetal da Universidade Estadual de Campinas.

2. Universidade Estadual de Campinas, Departamento de Botânica, Caixa Postal 6109, 13083-970 Campinas, SP, Brasil.

3. Universidade de São Paulo, Escola Superior de Agricultura Luiz de Queiroz, Departamento de Ciências Biológicas, Caixa Postal 9, 13418-900 Piracicaba, SP, Brasil.

4. Autor para correspondência: bagloria@esalq.usp.br
1988). Dentre as estruturas subterrâneas encontradas no Cerrado destacam-se os xilopódios, as raízes gemíferas, as raízes tuberosas, os sóboles e os rizóforos (Appezzato-da-Glória 2003).

Os sistemas subterrâneos possuem diferentes características morfo-anatômicas (Dietrich \& Figueiredo-Ribeiro 1985), podendo apresentar natureza estrutural complexa. Visto que os sistemas subterrâneos podem ter origem radicular, caulinar ou mista, as observações baseadas somente na morfologia externa são insuficientes para identificar sua natureza estrutural e, conseqüentemente, análises anatômicas são fundamentais. Dentre os trabalhos sobre anatomia de sistemas subterrâneos no Brasil, merecem destaque os 
de Menezes et al. (1969), Figueiredo (1972), Paviani (1972, 1977, 1978, 1987), Paviani \& Haridasan (1988), Appezzato-da-Glória \& Estelita (1995, 2000), Melo-dePinna \& Menezes (2003).

A presença de xilopódio foi relatada desde os primeiros estudos em plantas do cerrado (Rawitscher et al. 1943, Rawitscher \& Rachid 1946, Rachid 1947, Rizzini \& Heringer 1961, 1962, 1966, Rizzini 1963, 1965), tendo sido interpretada como uma adaptação às condições de seca. Os xilopódios originalmente descritos por Lindman (1906) caracterizam-se pela sua complexidade estrutural, consistência extremamente rígida e capacidade gemífera. Variam quanto à forma, de globosos a cilíndricos, segundo Appezzato-da-Glória \& Estelita (2000), ou mesmo sem forma definida, conforme mencionado por Rachid (1947).

Rizzini (1965), analisando a regeneração de plantas do Cerrado sujeitas à ação do fogo e do homem, ressaltou o papel da formação de gemas em raízes na sobrevivência das espécies, particularmente em regiões secas. Segundo o autor, ao contrário das sementes, as raízes gemíferas encontram-se protegidas no solo e mantêm conexão com o sistema subterrâneo, que lhes proporciona nutrição para seu desenvolvimento.

Em levantamentos realizados no cerrado, tem se verificado que diversas espécies possuem órgãos subterrâneos de reserva que acumulam grandes quantidades de frutanos (Figueiredo-Ribeiro et al. 1986, Tertuliano \& Figueiredo-Ribeiro 1993). Os frutanos apresentam outras funções além das de fonte de energia ou de carbono de reserva. Eles também estariam relacionados à tolerância de algumas espécies sujeitas aos estresses ambientais, principalmente no Cerrado, onde pode haver secas prolongadas e queimadas sendo, portanto, uma estratégia adaptativa das plantas às condições adversas do ambiente (Melo-de-Pinna \& Menezes 2003). Frutanos do tipo inulina já foram encontrados em diversos órgãos subterrâneos espessados, principalmente em espécies de Asteraceae (Figueiredo-Ribeiro et al. 1986).

Dada a importância ecológica dos sistemas subterrâneos, o objetivo desse trabalho é fornecer informações sobre a morfo-anatomia dos sistemas subterrâneos de Calea verticillata e Isostigma megapotamicum, pertencentes à família Asteraceae, com ênfase na formação de gemas caulinares.

\section{Material e métodos}

As duas espécies foram coletadas numa área de campo sujo do Estado de São Paulo, sendo que Isostigma megapotamicum (Spreng.) Sherff, na Estação Ecológica de

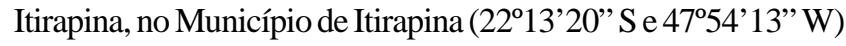
e Calea verticillata (Klatt) Pruski, numa propriedade particular "Fazenda Palmeira da Serra" no Município de Pratânia

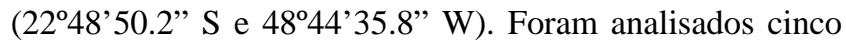
espécimes de I. megapotamicum e dois de $C$. verticillata.

As espécies foram identificadas por especialista e as exsicatas registradas e incorporadas ao acervo do Herbário da Escola Superior de Agricultura 'Luiz de Queiroz' (ESA) da Universidade de São Paulo, sob os seguintes registros: Calea verticillata ESA 83397 e Isostigma megapotamicum ESA 83398.

A análise anatômica foi realizada mediante coleta e fixação dos sistemas subterrâneos em FAA com etanol 50\% (Sass 1951). As secções (transversais e longitudinais), feitas à mão-livre e em micrótomo de deslize (150-200 $\mu \mathrm{m}$ de espessura), foram clarificadas com hipoclorito de sódio a $20 \%$, lavadas em água destilada, coradas com azul de astra e safranina aquosa (Gerlach 1984) e desidratadas em série etílica. Posteriormente imersas em acetato de butila $50 \%$ e $100 \%$ e montadas em resina sintética "Entellan".

Para determinar a origem das gemas, porções do sistema subterrâneo contendo gemas foram retiradas e fixadas em solução FAA com etanol 50\% (Sass 1951) e levadas a uma bomba de vácuo para a retirada do ar contido nos espaços intercelulares. Após a fixação, as amostras foram desidratadas em série etílica, incluídas em hidroxi-etil-metacrilato (Leica), seccionadas a $5 \mu \mathrm{m}$ de espessura, coradas com azul de toluidina para as análises anatômicas usuais (Sakai 1973) ou com corifosfina para análise de substâncias pécticas (Weis et al. 1988), seguindo a montagem em resina sintética "Entellan".

Testes microquímicos foram realizados utilizando-se amostras fixadas e não-fixadas dos sistemas subterrâneos de C. verticillata e I. megapotamicum. As secções foram feitas em micrótomo de deslize. A presença de substâncias lipofílicas foi visualizada pelo emprego de Sudan IV (vermelho Sudão IV) e Sudan black B (preto Sudão B) (Jensen 1962). Para a cristalização da inulina, foi utilizada a técnica descrita por Johansen (1940), submetendo o material a etanol 100\% por 48 horas. Os cristais foram visualizados em microscópio equipado com polarizador. As observações do material corado com corifosfina foram realizadas com microscópio de fluorescência modelo Leica DM LB, equipado com uma lâmpada de mercúrio HBO 50 com filtro $\mathrm{I}_{3}$ BP 450-490 nm (comprimento de onda). A presença de proteínas foi testada com "aniline blue black", (Ficher 1968) e os compostos fenólicos com cloreto férrico (Johansen 1940) e cloreto de zinco iodado (Strasburger 1913).

Fotomicrografias foram tiradas com o filme Ektachrome 64T para as análises em campo claro e com o filme Ektachrome 400 para imagens fluorescentes.

\section{Resultados}

Em Calea verticillata (Klatt) Pruski, o sistema subterrâneo é constituído pelo xilopódio que emite raízes 
adventícias espessadas (figura 1), esse sistema está localizado nas camadas superficiais do solo, possui consistência lenhosa e formato ovóide $(5,0 \mathrm{~cm}$ de comprimento e $3,5 \mathrm{~cm}$ de largura).

A análise anatômica do sistema subterrâneo nos planos de corte 1,2 e 3 , indicados na figura 1 , revela que a estrutura é altamente complexa e de natureza mista. Na porção proximal (figura 1 - plano 1), se observa auto-enxertia entre cinco eixos caulinares (figura 2). A auto-enxertia natural entre quatro eixos caulinares de um outro sistema subterrâneo pode ser visualizada na figura 3 . Observa-se que os eixos caulinares emitidos nos diferentes períodos não estão todos no mesmo plano. Na porção média do sistema subterrâneo (figura 1 - plano 2), a estrutura também é caulinar. Na porção distal (figura 1 - plano 3) se observa auto-enxertia entre eixos radiculares, sendo que a região central de um deles é mostrada na figura 4.

As gemas caulinares ocorrem em grupos (figuras $5,6)$ na porção proximal do sistema subterrâneo, localizada entre os planos 1 e 2 indicados na figura 1 . As gemas são protegidas por catafilos (figura 6) e se originam a partir da atividade cambial (figura 7).

O xilopódio e as raízes adventícias de Calea verticillata não apresentam cristais de inulina e outros compostos de reserva, pois o resultado dos testes microquímicos foi negativo. $\mathrm{O}$ sistema subterrâneo apresenta estruturas secretoras no floema secundário (figura 8). Nas secções longitudinais é possível verificar que essas estruturas são alongadas constituindo canais secretores. Nos materiais fixados é mais difícil visualizar a secreção dentro dos canais. Nas amostras não fixadas, a secreção dos canais é corada com o Sudan IV. As raízes adventícias de Calea verticillata também apresentam canais secretores.

Em Isostigma megapotamicum (Spreng.) Sherff, o sistema subterrâneo é constituído pelo xilopódio que emite raízes adventícias delgadas (figura 9). Nem sempre os xilopódios apresentam o mesmo formato. $\mathrm{O}$ xilopódio ilustrado na figura 9 é ovóide como na espécie Calea verticillata, com $6 \mathrm{~cm}$ de comprimento e $5,5 \mathrm{~cm}$ de largura; sua porção proximal apresenta várias gemas caulinares (figura 10), concentrando-se até $2,5 \mathrm{~cm}$ do ápice, e sua porção distal, mais dilatada, emite muitas raízes (figura 9).

As gemas caulinares presentes nesse sistema subterrâneo (figura 11) se originam a partir da atividade cambial (figura 12).

Até a porção mediana do sistema subterrâneo (plano de corte 1 da figura 9) há vários eixos caulinares autoenxertados. No corte transversal de um desses eixos (figura 13), o cilindro central apresenta maturação centrífuga do xilema primário (figura 14). O xilopódio após ser submetido à técnica para a cristalização da inulina apresenta cristais de inulina predominantemente no parênquima xilemático (figura 15).

O sistema subterrâneo apresenta estruturas secretoras que, em secção transversal (figuras 16, 17), possuem epitélio secretor delimitando o lume, o qual é preenchido por uma secreção de coloração avermelhada in vivo (figuras 16,18). A secreção é uma emulsão e se apresenta em forma de gotas no interior dos canais (figuras 19-21), de coloração amarelada (no lume do canal) e alaranjada (no epitélio) quando corada com a corifosfina e observada em microscópio de fluorescência, indicando a presença de substâncias pécticas (figuras 20, 21). A análise dos cortes longitudinais (figuras 18, 19) revela que tais estruturas são longas tratando-se de canais ou ductos. Esses canais ocorrem tanto no floema (figura 22) como no xilema secundários (figura 23) e se originam a partir de células derivadas do câmbio (figura 23).

Testes microquímicos realizados com o Sudan black B (figuras 17, 19) confirmam a natureza lipídica da secreção. Essa mesma secreção obteve resposta negativa para proteínas totais através do teste com "aniline blue black". Também obteve resposta negativa para cloreto férrico, cloreto de zinco iodado e para "aniline blue black" em todos os tecidos do xilopódio, sugerindo a ausência de compostos fenólicos, amido e de proteínas totais, respectivamente, nesses tecidos.

\section{Discussão}

Os sistemas subterrâneos de Calea verticillata (Klatt) Pruski e Isostigma megapotamicum (Spreng.) Sherff são bastante complexos, altamente lignificados e caracterizados pela auto-enxertia entre eixos caulinares (reflexo da sua elevada capacidade gemífera). Essas características morfo-anatômicas permitem denominar esses sistemas de xilopódio (Appezzato-da-Glória 2003). Segundo a autora, os xilopódios originalmente descritos por Lindman (1906) caracterizam-se pela sua complexidade estrutural, consistência extremamente rígida e capacidade gemífera. Também Rachid (1947), baseando-se apenas na morfologia externa das estruturas, comentou que o xilopódio poderia ser caulinar e/ou radicular. Com as análises anatômicas, Paviani $(1977,1978)$ considerou o xilopódio, em Brasilia sickii G.M. Barroso, uma unidade morfológica, porém não anatômica. De acordo com a autora, a estrutura do xilopódio às vezes é caulinar e, 

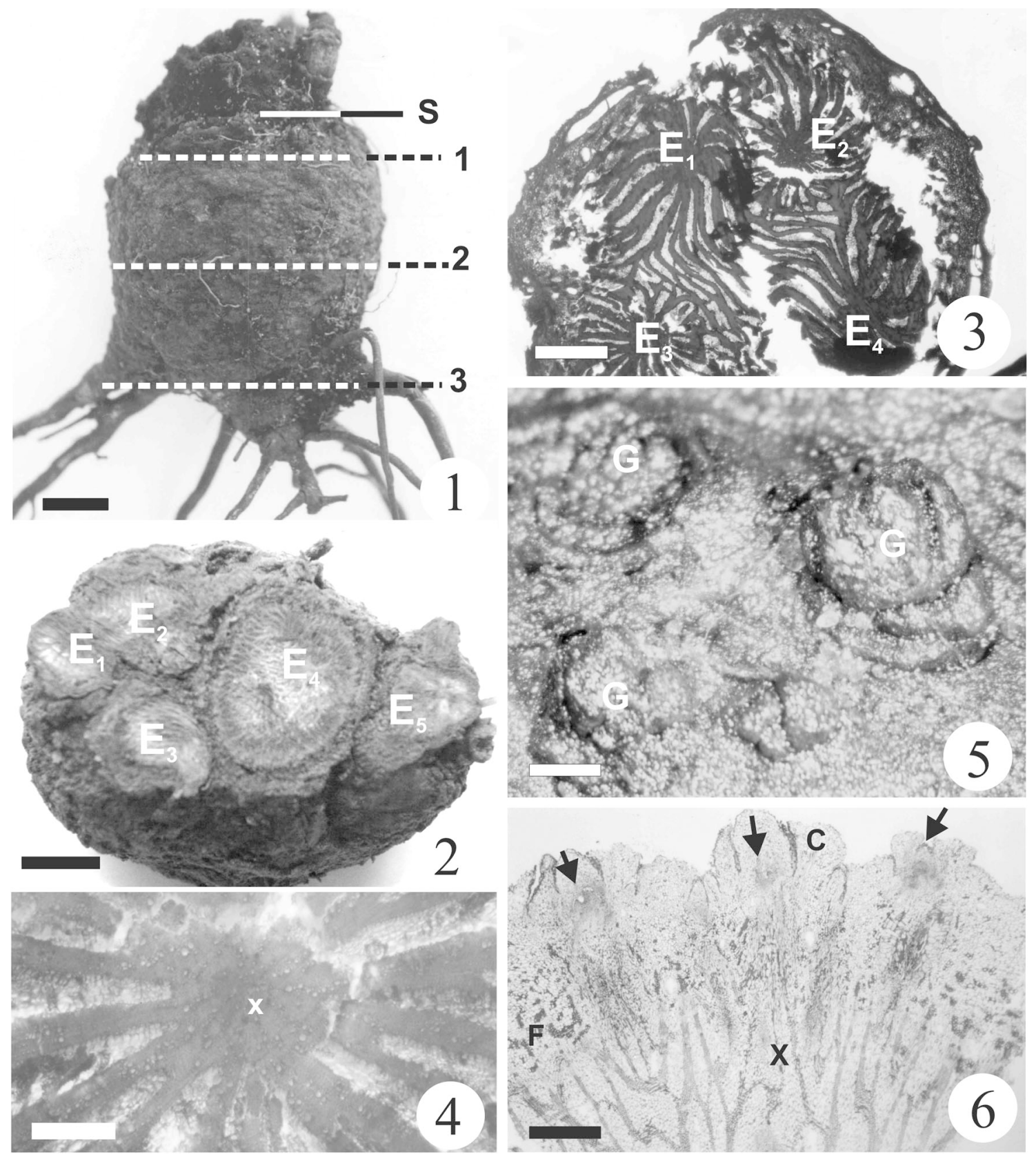

Figuras 1-6. Calea verticillata (Klatt) Pruski. 1. Visão geral do xilopódio, onde $\mathrm{S}$ corresponde ao nível do solo, e os números 1,2 e 3 aos planos de corte analisados anatomicamente. 2. Vista frontal da porção superior de outro xilopódio, com cinco eixos caulinares (E) enxertados naturalmente. 3. Secção transversal do xilopódio no plano 1, evidenciando quatro eixos caulinares auto-enxertados (E). 4. Estrutura radicular no plano 3 do xilopódio ( $\mathrm{x}=$ xilema primário). 5. Gemas caulinares $(\mathrm{G})$ localizadas entre os planos 1 e 2 do xilopódio. 6. Secção longitudinal das gemas do xilopódio (setas = gemas; $\mathrm{C}=$ catafilo; $\mathrm{F}=$ floema; $\mathrm{X}=\mathrm{xilema}$ ). Barras $=1 \mathrm{~cm}(1,5), 2 \mathrm{~cm}(2,4), 0,5 \mathrm{~cm}(3), 0,12 \mathrm{~cm}(6)$.

Figures 1-6. Calea verticillata (Klatt) Pruski. 1. General view of the xylopodium, in which S corresponds to soil level and numbers 1, 2 and 3 to anatomical sectioning levels. 2. Frontal view of the upper part of another xylopodium, with natural selfgrafting of five shoots (E). 3. Transverse section of level 1 of the xylopodium showing self-grafting of four shoots (E). 4. Root structure of the level 3 of the xylopodium ( $x=$ primary xylem). 5. Shoot buds $(\mathrm{G})$ located between levels 1 and 2 of the xylopodium. 6. Longitudinal section of the xylopodium buds (arrows $=$ shoot buds; $\mathrm{C}=$ cataphyll; $\mathrm{F}=\mathrm{phloem} ; \mathrm{X}=\mathrm{xylem}$ ). Bars $=1 \mathrm{~cm}(1,5), 2 \mathrm{~cm}(2,4), 0,5 \mathrm{~cm}(3), 0,12 \mathrm{~cm}(6)$. 
em outras vezes, radicular. Fato também confirmado por Appezzato-da-Glória \& Estelita $(1995,2000)$ em Mandevilla illustris (Vell.) Woodson e M. velutina (Mart. ex Stadelm.) Woodson.

A complexidade estrutural dos xilopódios está relacionada ao processo natural de enxertia entre ramos e raízes que são emitidos pela planta ao longo de seu desenvolvimento como verificado em Calea verticillata e Isostigma megapotamicum e em outras espécies do cerrado (Paviani 1977, 1978; Appezzato-da-Glória \& Estelita 1995, 2000). A emissão periódica de ramos observada em C. verticillata e I. megapotamicum, em função das gemas presentes nos xilopódios, confere às espécies a capacidade de sobrevivência às condições do Cerrado, especialmente nos períodos de déficit hídrico que, em geral, estão associados à ação do fogo, conforme salientado por Rizzini \& Heringer (1961) para outras espécies providas de xilopódio.

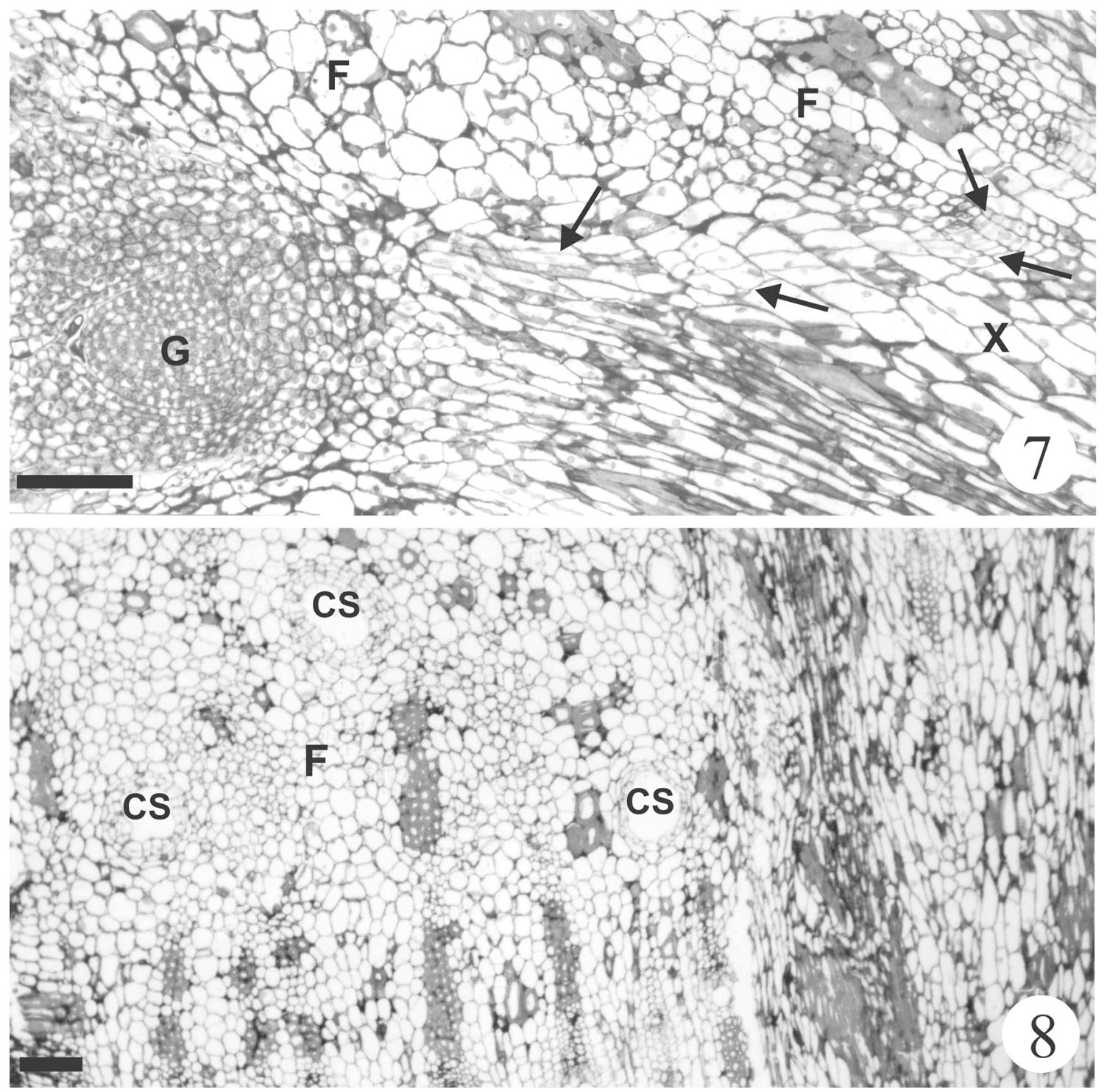

Figuras 7-8. Calea verticillata (Klatt) Pruski. 7. Gema caulinar (G) do xilopódio em início de formação. A gema é lateralmente delimitada pelo floema secundário $(\mathrm{F})$, confirmando a origem cambial (setas), $\mathrm{X}=$ xilema. 8. Canais secretores no floema secundário $(\mathrm{CS}=$ canal secretor; $\mathrm{F}=$ floema). Barras $=100 \mu \mathrm{m}(7), 200 \mu \mathrm{m}(8)$.

Figures 7-8. Calea verticillata (Klatt) Pruski. 7. Beginning of formation of xylopodium shoot bud. The shoot bud is surrounded by the phloem, confirming its cambial origin (arrow = cambium; $\mathrm{G}=$ shoot bud; $\mathrm{F}=$ phloem; $\mathrm{X}=\mathrm{xylem}$ ). 8 . Secretory ducts of the secondary phloem $(\mathrm{CS}=$ secretory ducts; $\mathrm{F}=$ phloem $)$. Bars $=100 \mu \mathrm{m}(7), 200 \mu \mathrm{m}(8)$. 


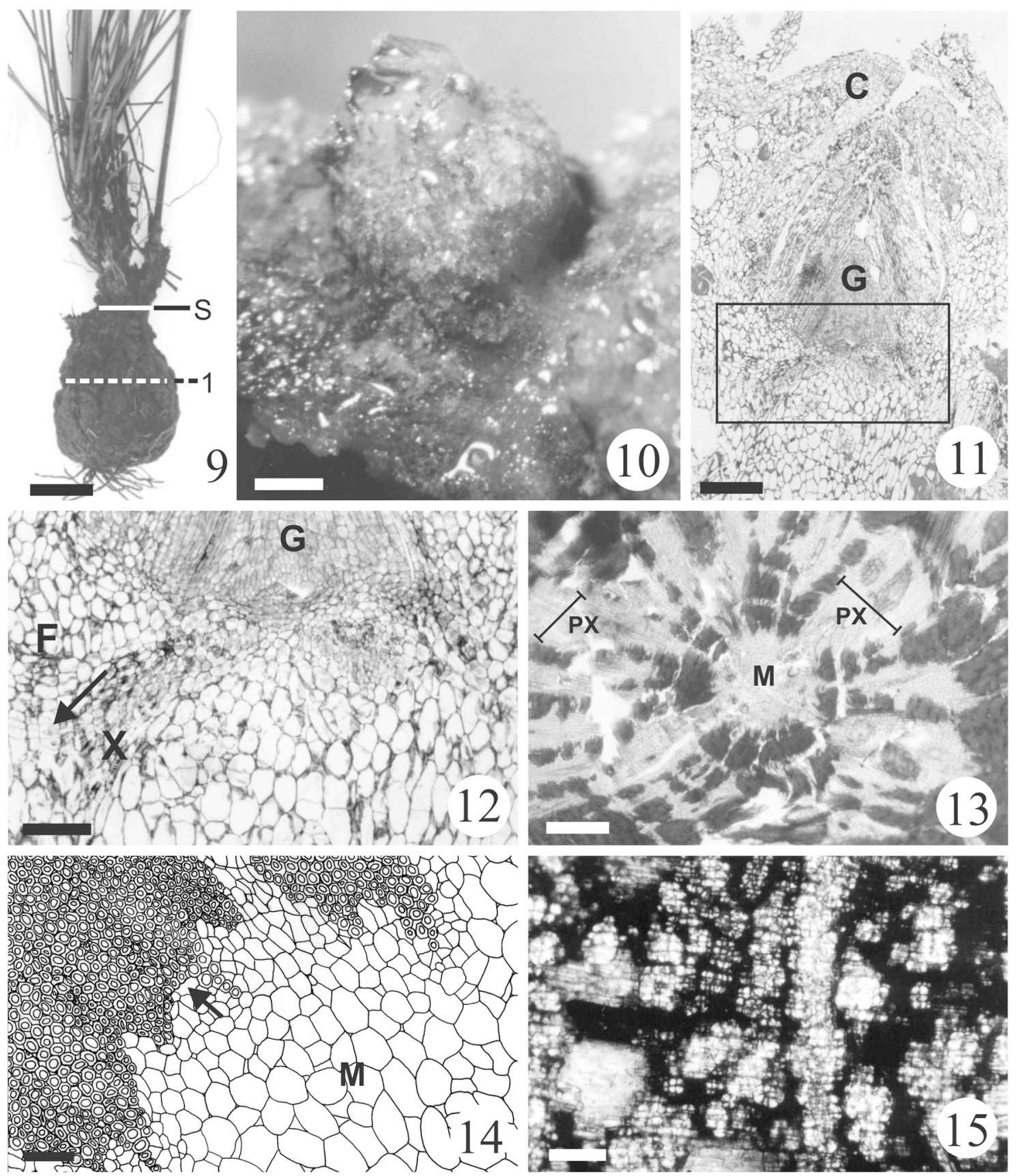

Figuras 9-15. Isostigma megapotamicum (Spreng.) Sherff. 9. Vista geral do xilopódio onde S corresponde ao nível do solo, e o número 1 ao plano de corte analisado anatomicamente. 10. Vista geral da gema na porção proximal do xilopódio. 11. Secção longitudinal de uma gema $(\mathrm{G})$ do xilopódio, cujo detalhe é mostrado na figura $12(\mathrm{C}=$ catafilo $) .12$. Detalhe do setor indicado na figura 11 mostrando a origem cambial da gema (seta = câmbio; $F=$ floema; $G=$ gema; $X=$ xilema). 13 . Secção transversal do xilopódio no plano 1 da figura $9(\mathrm{M}=$ medula; $\mathrm{PX}=$ parênquima xilemático). 14. Detalhe da figura anterior mostrando o xilema endarco (seta) confirmando a estrutura caulinar do xilopódio $(\mathrm{M}=$ medula). 15. Cristais de inulina, no parênquima xilemático, observados sob luz polarizada. Barras $=2 \mathrm{~cm}$ (9), $800 \mu \mathrm{m}$ (10), $400 \mu \mathrm{m}$ (11), $150 \mu \mathrm{m}$ (12), $900 \mu \mathrm{m}$ (13), $50 \mu \mathrm{m}(14), 200 \mu \mathrm{m}(15)$.

Figures 9-15. Isostigma megapotamicum (Spreng.) Sherff. 9. General view of the xylopodium, in which S corresponds to soil level, and number 1 to anatomical sectioning level. 10. General view of the xylopodium bud. 11. Longitudinal section of the xylopodium shoot bud $(\mathrm{G})$, whose detail is showed in figure $12(\mathrm{C}=$ cataphyll). 12. Detail of the sector indicated on figure 11, showing the cambial origin of the xylopodium shoot bud $(G)$. (arrow $=$ cambium; $F=$ phloem; $G=$ bud; $X=x y l e m)$. 13. Transverse section of the xylopodium. $(\mathrm{M}=$ pith; $\mathrm{PX}=$ xylem parenchyma). 14. Detail of the previous figure showing the endarch xylem (arrow) confirming the cauline structure of the xylopodium $(\mathrm{M}=$ pith). 15. Crystals of inulin, in the xylem parenchyma cells, observed by polarized light. Bars $=2 \mathrm{~cm}$ (9), $800 \mu \mathrm{m}$ (10), $400 \mu \mathrm{m}$ (11), $150 \mu \mathrm{m}$ (12), $900 \mu \mathrm{m}$ (13), $50 \mu \mathrm{m}(14), 200 \mu \mathrm{m}(15)$. 

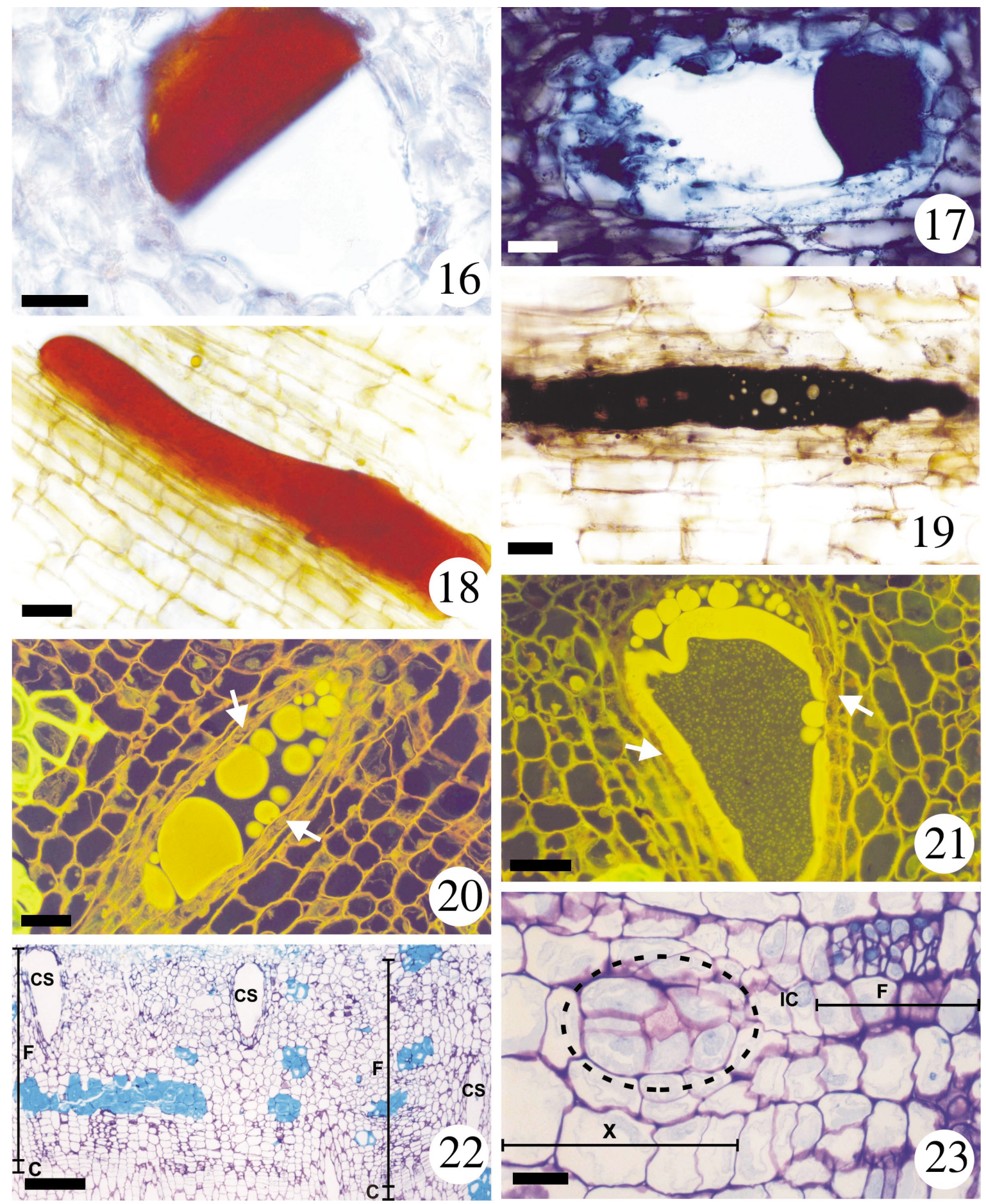

Figuras 16-23. Isostigma megapotamicum (Spreng.) Sherff. Secções transversais (16, 17, 20-23) e longitudinais (18, 19). 16, 18. Canal cuja secreção é avermelhada. 17 e 19. Mostram a secreção do canal corada com Sudan black B. 20 e 21. Canal com secreção em gotas corada pela corifosfina (setas = epitélio). 22. Canais secretores $(\mathrm{CS})$ no floema secundário $(\mathrm{F})$. $(\mathrm{C}=$ câmbio). 23. Canal secretor (tracejado) originado a partir de derivadas do câmbio ( $\mathrm{IC}=$ iniciais cambiais; $\mathrm{F}=$ floema secundário; $\mathrm{X}=$ xilema secundário). Barras $=30 \mu \mathrm{m}(16,23), 50 \mu \mathrm{m}(17-20), 250 \mu \mathrm{m}(21), 300 \mu \mathrm{m}(22)$.

Figures 16-23. Isostigma megapotamicum (Spreng.) Sherff. Transversal sections (16, 17, 20-23) and longitudinal sections (18, 19). 16, 18. Canal whose secretion is reddish. 17 and 19. Canal showing the secretion stained by Sudan black B. 20 and 21. Secretory canals showing secretion with drops coriphosphine-stained (arrows = epithelium). 22. Secretory canals (CS) of the secondary phloem (F). C = cambium. 23. Secretory duct (hatched) originated from cambium derivate cells (IC $=$ cambial initials; $F=$ secondary phloem; $X=$ secondary xylem). Bars $=30 \mu \mathrm{m}(16,23), 50 \mu \mathrm{m}(17-20), 250 \mu \mathrm{m}(21), 300 \mu \mathrm{m}(22)$. 
As gemas do xilopódio de Calea verticillata e de Isostigma megapotamicum são originadas pela atividade cambial. Embora Paviani (1987) tenha considerado como padrão para os xilopódios a origem das gemas a partir da desdiferenciação de células parenquimáticas proliferadas, Appezzato-da-Glória e Estelita (1995) já haviam verificado a origem cambial das gemas em Mandevilla illustris e M. velutina.

Em relação às reservas, o xilopódio e as raízes adventícias de Calea verticillata não apresentaram cristais de inulina ou amido. Por sua vez, no xilopódio de Isostigma megapotamicum foi detectada a presença de cristais de inulina, confirmando as observações de Tertuliano \& Figueiredo-Ribeiro (1993) quanto à ocorrência de frutanos no sistema subterrâneo dessa espécie. Em I. megapotamicum, os cristais de inulina são visualizados apenas no parênquima xilemático, enquanto em outras Asteraceae podem ocorrer no parênquima cortical, periciclo e parênquima axial do floema e do xilema (Melo-de-Pinna \& Menezes 2003). Segundo as autoras, os frutanos estariam relacionados à tolerância de algumas espécies sujeitas aos estresses ambientais, principalmente no Cerrado, onde pode haver secas prolongadas e queimadas.

Os xilopódios de Calea verticillata e de Isostigma megapotamicum apresentam canais secretores de substâncias lipídicas. Em I. megapotamicum os canais ocorrem tanto no floema como no xilema secundários, enquanto que, em $C$. verticillata, ocorrem apenas no floema secundário. A posição dos canais secretores em raízes de Asteraceae pode variar entre espécies de uma mesma tribo ou de tribos diferentes (Melo-dePinna \& Menezes 2003). Calea verticillata e Isostigma megapotamicum pertencem à tribo Heliantheae e, segundo dados apresentados pelas autoras, os canais secretores podem ocorrer no córtex interno, periciclo e no floema secundário nas raízes de plantas dessa tribo. A despeito da importância taxonômica das estruturas secretoras para as Asteraceae (Castro et al. 1997) não há registro na literatura sobre a ocorrência dos canais secretores em xilopódios dessa família. Além disso, pouco se sabe sobre o papel ecológico das estruturas secretoras em sistemas subterrâneos de espécies do Cerrado, tornando necessários estudos sobre a interação da fauna subterrânea com tais sistemas.

Agradecimentos - Ao Prof. Dr. Lindolpho Capellari Júnior, pela ilustração botânica e ao Prof. Dr. Vinícius Castro Souza, pela identificação do material botânico, ambos do Departamento de Ciências Biológicas ESALQ/USP. À farmacêutica Marli Kasue Misaki Soares, pelo apoio técnico na preparação das lâminas e na elaboração das pranchas para a publicação. À Fundação de Amparo à Pesquisa do Estado de São Paulo, pelo financiamento do projeto Biota (n. 00/12469-3) e da bolsa de Mestrado (n. 01/12138-0).

\section{Referências bibliográficas}

APPEZZATO-DA-GLÓRIA, B. 2003. Morfologia de sistemas subterrâneos: histórico e evolução do conhecimento no Brasil. Ed. Alexandre Sene Pinto, Ribeirão Preto.

APPEZZATO-DA-GLÓRIA, B. \& ESTELITA, M.E.M. 1995. Caracteres anatômicos da propagação vegetativa de Mandevilla illustris (Vell.) Woodson e de M. velutina (Mart. ex Stadelm.) Woodson - Apocynaceae. In Anais do IX Congresso da Sociedade Botânica de São Paulo, Ilha Solteira, p.5-13.

APPEZZATO-DA-GLÓRIA, B. \& ESTELITA, M.E.M. 2000. The developmental anatomy of the subterranean system in Mandevilla illustris (Vell.) Woodson and M. velutina (Mart. ex Stadelm.) Woodson (Apocynaceae). Revista Brasileira de Botânica 23:7-35.

CASTRO, M.M., LEITÃO FILHO, H.F. \& MONTEIRO, W.R. 1997. Utilização de estruturas secretoras na identificação dos gêneros de Asteraceae de uma vegetação de Cerrado. Revista Brasileira de Botânica 20:163-174.

DIETRICH, S.M.C. \& FIGUEIREDO-RIBEIRO, R.C.L. 1985. Organos subterraneos y propagacion vegetativa en plantas de los cerrados brasileros. Medio Ambiente 7:45-52.

FIGUEIREDO, R.C.L. 1972. Sobre a anatomia dos órgãos vegetativos de Ocimum nudicaule Benth. (Labiatae). Anais da Academia Brasileira de Ciências 44:549-570.

FIGUEIREDO-RIBEIROR.C.L., DIETRICH, S.M.S., CHU, E.P., MACHADO DE CARVALHO, M.A., VIEIRA, C.C.J. \& GRAZIANO, T.T. 1986. Reserve carbohydrates in underground organs of native Brazilian plants. Revista Brasileira de Botânica 9:159-166.

FICHER, D.B. 1968. Protein staining of ribboned epon sections for light microscopy. Histochemie 16:92-96.

GERLACH, D. 1984. Botanische mikrotechnik. Thieme Verlag, Stuttgart.

JENSEN, W. A. 1962. Botanical histochemistry: principle and practice. W. H. Freeman, San Francisco.

JOHANSEN, D.A., 1940. Plant microtechnique. McGraw-Hill Book Company, New York.

LINDMAN, C.A.M. 1906. A vegetação no Rio Grande do Sul. Loefgren, Porto Alegre.

MANTOVANI, W. \& MARTINS, F.R. 1988. Variações fenológicas das espécies de cerrado da reserva Biológica de Moji-Guaçú, São Paulo. Revista Brasileira de Botânica 11:101-112.

MELO-DE-PINNA, G.F.A. \& MENEZES, N.L. 2003. Meristematic endodermis and secretory structures in adventitious roots of Richterago Kuntze (MutisieaeAsteraceae). Revista Brasileira de Botânica 26:1-10. 
MENEZES, N.L., HANDRO, W. \& MELLO CAMPOS, J.F.B. 1969. Estudos anatômicos em Pfaffia jubata Mart. Boletim da Faculdade de Filosofia Ciências e Letras da Universidade de São Paulo, 331 (Botânica) 24:197-237.

PAVIANI, T.I. 1972. Estudo morfológico e anatômico de Brasilia sickii G.M. Barroso: I. Revista Brasileira de Biologia 32:451-472.

PAVIANI, T.I. 1977. Estudo morfológico e anatômico de Brasilia sickii G. M. Barroso. II: Anatomia da raiz, do xilopódio e do caule. Revista Brasileira de Biologia 37:307-324.

PAVIANI, T.I. 1978. Anatomia vegetal e cerrado. Ciência e Cultura 30:1076-1086.

PAVIANI, T.I. 1987. Anatomia do desenvolvimento do xilopódio de Brasilia sickii G. M. Barroso. Estágio inicial. Ciência e Cultura 39:399-405.

PAVIANI, T.I. \& HARIDASAN, M. 1988. Tuberosidade em Vochysia thyrsoidea Pohl (Vochysiaceae). Ciência e Cultura 40:998-1003.

RACHID, M. 1947. Transpiração e sistemas subterrâneos da vegetação de verão dos campos Cerrados de Emas. Boletim da Faculdade de Filosofia Ciências e Letras da Universidade de São Paulo, 80 (Botânica) 5:5-140.

RAWITSCHER, F. \& RACHID, M. 1946. Troncos subterrâneos de plantas brasileiras. Anais da Academia Brasileira de Ciências 18:261-280.

RAWITSCHER, F., FERRI, M.G. \& RACHID, M. 1943. Profundidade dos solos e vegetação em campos cerrados do Brasil Meridional. Anais da Academia Brasileira de Ciências 15:267-294.
RIZZINI, C.T. 1963. O fator edáfico na formação do xilopódio de Mimosa multipinna Benth. Anais da Academia Brasileira de Ciências 35:75-77.

RIZZINI, C.T. 1965. Estudos experimentais sobre o xilopódio e outros órgãos tuberosos de plantas do cerrado. Anais da Academia Brasileira de Ciências 37:87-113.

RIZZINI, C.T. \& HERINGER, E.P. 1961. Underground organs of plants from some southern Brazilian savannas, with special reference to the xylopodium. Phyton 17:105-124.

RIZZINI, C.T. \& HERINGER, E.P. 1962. Studies on the underground organs of trees and shrubs from some southern Brazilian savannas. Anais da Academia Brasileira de Ciências 34:235-247.

RIZZINI, C.T. \& HERINGER, E.P. 1966. Estudo sobre os sistemas subterrâneos difusos de plantas campestres. Anais da Academia Brasileira de Ciências 38:85-112.

SAKAI, W.S. 1973. Simple method for differential staining of paraffin embedded plant material using toluidine blue O. Stain Technology 48:247-249.

SASS, J.E. 1951. Botanical microtechnique. Iowa State University, Ames.

STRASBURGER, E. 1913. Handbook of practical botany. George Allen, London.

TERTULIANO, M.F. \& FIGUEIREDO-RIBEIRO, R.C.L. 1993. Distribution of fructose polymers in herbaceous species of Asteraceae from the cerrado. New Phytologist 123:741-749.

WEIS, K.G., POLITO, V.S. \& LABAVITCH, J.M. 1988. Microfluorometry of pectic materials in the dehiscence zone of almond (Prunus dulcis (Mill.) DA Webb) fruits. Journal of histochemistry and citochemistry 36:1037-1041. 